Case Report

\title{
Aggressive Systemic Mastocytosis in Association with Pure Red Cell Aplasia
}

\author{
Dhauna Karam $\mathbb{D}^{1,2}$ Sean Swiatkowski, ${ }^{1,2}$ Mamata Ravipati, ${ }^{1,2}$ and Bharat Agrawal ${ }^{1,2}$ \\ ${ }^{1}$ Rosalind Franklin University, 3333 Green Bay Road, North Chicago, IL 60064, USA \\ ${ }^{2}$ Captain James A. Lovell Federal Health Care Center, 3001 Green Bay Road, North Chicago, IL 60064, USA \\ Correspondence should be addressed to Dhauna Karam; dhauna.karam@gmail.com
}

Received 13 March 2018; Revised 20 May 2018; Accepted 20 June 2018; Published 8 July 2018

Academic Editor: Håkon Reikvam

Copyright $(2018$ Dhauna Karam et al. This is an open access article distributed under the Creative Commons Attribution License, which permits unrestricted use, distribution, and reproduction in any medium, provided the original work is properly cited.

Aggressive systemic mastocytosis (ASM) is characterized by mast cell accumulation in systemic organs. Though ASM may be associated with other hematological disorders, the association with pure red cell aplasia (PRCA) is rare and has not been reported. Pure red cell aplasia (PRCA) is a syndrome, characterized by normochromic normocytic anemia, reticulocytopenia, and severe erythroid hypoplasia. The myeloid and megakaryocytic cell lines usually remain normal. Here, we report an unusual case of ASM, presenting in association with PRCA and the management challenges.

\section{Introduction}

Aggressive systemic mastocytosis is a rare disorder characterized by abnormal accumulation of mast cells in bone marrow and internal organs (liver, spleen, lymph nodes, and gastrointestinal tract) [1]. Mastocytosis was initially classified as one of the subtypes of "myeloproliferative neoplasms (MPN)." In the 2016 revision of the World Health Organization (WHO) classification of tumors of the hematopoietic and lymphoid tissues, mastocytosis was classified as a separate entity $[2,3]$. Chemical mediators such as tumor necrosis factor produced by mast cells can suppress erythropoiesis, and some mast cell diseases can cause hypoplastic anemia, though the pathogenesis is not clear. Our case report highlights an unusual and rare presentation of ASM with PRCA. Such an association has not been reported in the literature, except in one case report where mast cell activation disorder and PRCA occurred together [4].

\section{Case Presentation}

2.1. Patient's Symptoms/History. A 64-year-old white male, with past medical history of depression, presented with progressive weakness, unintentional weight loss, and exercise intolerance since past 1 month. He was a very healthy and active person; he enjoyed biking and rollerblading. The above symptoms were very unusual for him. The patient reported intermittent episodes of epistaxis, 3-4 times a week since the past month, lasting for a few minutes. He also endorsed 2-3 episodes of loose stools daily since the past month. Of note, the patient had history of exposure to Agent Orange between years 1969 and 1971; the first exposure was forty-five years earlier. Physical examination revealed stable vital signs with a palpable spleen of six finger-breadths below the left costal margin and mild hepatomegaly. Cardiopulmonary, lymphatic, and dermatologic examination, including Darrier's sign were all negative.

2.2. Diagnosis. On admission, the patient was found to have a hemoglobin count of $5.1 \mathrm{~g} / \mathrm{dl}$, which was a significant drop from the patient's baseline hemoglobin of $13-14 \mathrm{~g} / \mathrm{dl}$. Other basic laboratory studies are presented in Table 1. Urine analysis, stool for blood test, serum haptoglobulin, LDH, hepatitis $\mathrm{B}$ and $\mathrm{C}$ testing, $\mathrm{PNH}$ by flow cytometry, and hemochromatosis gene mutation were normal or negative. Serum tryptase level was elevated at $1110 \mathrm{ng} / \mathrm{ml}$ (nor$\mathrm{mal}<11.4 \mathrm{ng} / \mathrm{ml}$ ). Bone marrow biopsy and clot section performed as a part of anemia workup revealed hypercellularity with markedly increased maturing granulopoiesis 
TABLE 1: Laboratory values.

\begin{tabular}{|c|c|c|c|}
\hline Laboratory analysis & Patient's values on initial hospitalization & Patient's values on second hospitalization & Normal range \\
\hline Hemoglobin & $5.1 \mathrm{~g} / \mathrm{dl}$ & $7.4 \mathrm{~g} / \mathrm{dl}$ & $13-17$ \\
\hline $\mathrm{MCV}$ & $97 \mathrm{fl}$ & $90.4 \mathrm{fl}$ & $82-99$ \\
\hline $\mathrm{MCHC}$ & $31.5 \mathrm{~g} / \mathrm{dl}$ & $32.9 \mathrm{~g} / \mathrm{dl}$ & $31-37$ \\
\hline WBC count & $6 \mathrm{k} / \mu \mathrm{L}$ & $5.1 \mathrm{k} / \mu \mathrm{L}$ & $4-10$ \\
\hline Platelet count & $91 \mathrm{k} / \mu \mathrm{L}$ & $90 \mathrm{k} / \mu \mathrm{L}$ & $150-400$ \\
\hline Absolute eosinophil count & $2 \mathrm{k} / \mu \mathrm{L}$ & $2 \mathrm{k} / \mu \mathrm{L}$ & \\
\hline Neutrophil & $30 \%$ & $30.8 \%$ & $40-80$ \\
\hline Lymphocyte & $24 \%$ & $23.5 \%$ & $15-45$ \\
\hline Eosinophil & $33.5 \%$ & $33.3 \%$ & $0-6$ \\
\hline Basophil & $0 \%$ & $0 \%$ & $0-2$ \\
\hline Glucose & $140 \mathrm{mg} / \mathrm{dl}$ & $117 \mathrm{mg} / \mathrm{dl}$ & $70-99$ \\
\hline BUN & $16 \mathrm{mg} / \mathrm{dl}$ & $14 \mathrm{mg} / \mathrm{dl}$ & $7-21$ \\
\hline Creatinine & $0.87 \mathrm{mg} / \mathrm{dl}$ & $0.83 \mathrm{mg} / \mathrm{dl}$ & $0.67-1.17$ \\
\hline AST & $16 \mathrm{U} / \mathrm{L}$ & $96 \mathrm{U} / \mathrm{L}$ & $10-37$ \\
\hline ALT & $22 \mathrm{U} / \mathrm{L}$ & $55 \mathrm{U} / \mathrm{L}$ & $10-65$ \\
\hline Alkaline phosphatase & $475 \mathrm{U} / \mathrm{L}$ & $130 \mathrm{U} / \mathrm{L}$ & $50-136$ \\
\hline Total bilirubin & $0.8 \mathrm{mg} / \mathrm{dl}$ & $21.3 \mathrm{mg} / \mathrm{dl}($ direct $16.7 \mathrm{mg} / \mathrm{dl})$ & $0-1$ \\
\hline Stool occult blood & Negative & & \\
\hline Haptoglobulin & $214 \mathrm{mg} / \mathrm{dl}$ & & $30-200$ \\
\hline Reticulocyte \% & 0.6 & & $0.5-2.5$ \\
\hline $\mathrm{LDH}$ & $147 \mathrm{U} / \mathrm{L}$ & & $84-246$ \\
\hline $\mathrm{PT}$ & $12.8 \mathrm{~s}$ & $27 \mathrm{~s}$ & $9-12$ \\
\hline INR & 1.2 & & $0.9-1.1$ \\
\hline aPTT & $33.1 \mathrm{~s}$ & $77 \mathrm{~s}$ & $23-34$ \\
\hline Iron & $202 \mu \mathrm{g} / \mathrm{dl}$ & & $65-175$ \\
\hline TIBC & $203 \mu \mathrm{g} / \mathrm{dl}$ & & $250-450$ \\
\hline Iron saturation & $100 \%$ & & $10-50$ \\
\hline Ferritin & $949.9 \mathrm{ng} / \mathrm{ml}$ & & $26-388$ \\
\hline Vitamin B12 & $1680 \mathrm{pg} / \mathrm{ml}$ & & $193-986$ \\
\hline Folate & $19.6 \mathrm{ng} / \mathrm{ml}$ & & $8.7-55.4$ \\
\hline TSH & $1.48 \mathrm{uIU} / \mathrm{ml}$ & & $0.358-3.74$ \\
\hline Fibrinogen & & 410 & \\
\hline SPEP-protein & $6.8 \mathrm{~g} / \mathrm{dl}$ & & $6.4-8.2$ \\
\hline Albumin & $2.8 \mathrm{~g} / \mathrm{dl}$ & $1.3 \mathrm{~g} / \mathrm{dl}$ & $3.5-5.0$ \\
\hline Alpha-1 globulin & $0.5 \mathrm{~g} / \mathrm{dl}$ & & $0.2-0.4$ \\
\hline Alpha-2 globulin & $1.0 \mathrm{~g} / \mathrm{dl}$ & & $0.5-1.0$ \\
\hline Beta globulin & $0.7 \mathrm{~g} / \mathrm{dl}$ & & $0.5-1.1$ \\
\hline Gamma globulin & $1.8 \mathrm{~g} / \mathrm{dl}$ & & $0.6-1.5$ \\
\hline
\end{tabular}

with increased number of neutrophils and eosinophils. Erythropoiesis was markedly decreased with only very rare proerythroblasts present (Figure 1). Megakaryocytosis with dysmegakaryopoiesis was also appreciated. Several perivascular fibrotic areas containing mast cell aggregates were also identified (Figures 2 and 3). The mast cells were positive for mast cell tryptase and aberrant expression of CD2 and CD25 (Figures 4 and 5). c-KIT and D $816 \mathrm{~V}$ mutations were detected. The above findings were suggestive of ASM. FISH, cytogenetic, and flow cytometric analyses were unrevealing. Parvovirus immunostain was negative.

2.3. Treatment. After the diagnosis of ASM and PRCA, the patient left our hospital against medical advice. He became completely transfusion-dependent and was receiving weekly red cell transfusions from a nearby community hospital. He returned to our hospital after 5 weeks with worsening anemia, thrombocytopenia, liver function tests, and coagulopathy. The patient reported lack of transportation and

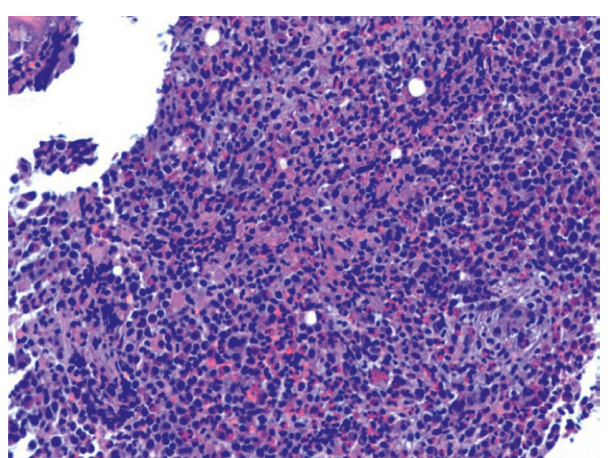

FIGURE 1: Area of hypercellular bone marrow with red cell aplasia.

social support to return to hospital for treatment. Peripheral smear revealed normochromic normocytic anemia with occasional ovalocyte, rare target cell, and dacrocyte. No nucleated red blood cell was identified. Granulocytes appeared mature without abnormal granulation or segmentation. 


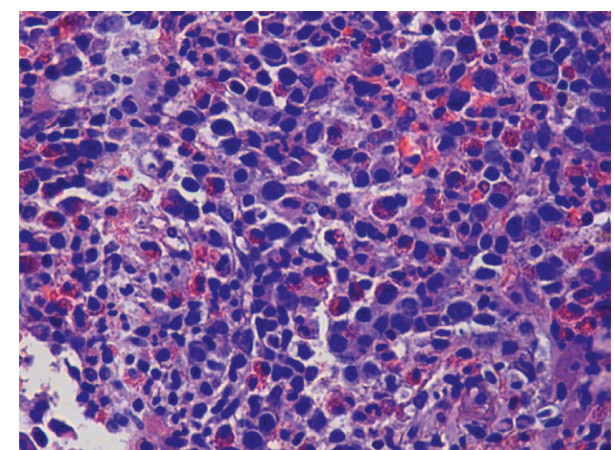

FIGURE 2: Bone marrow with hypercellularity and increased mast cells.

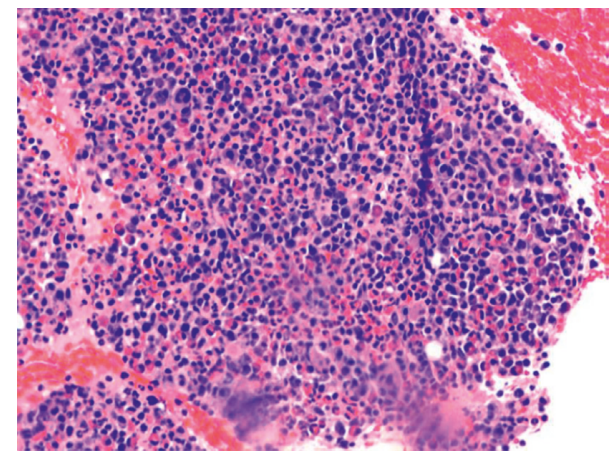

FIGURE 3: Clot section which shows hypercellularity and increased mast cells.

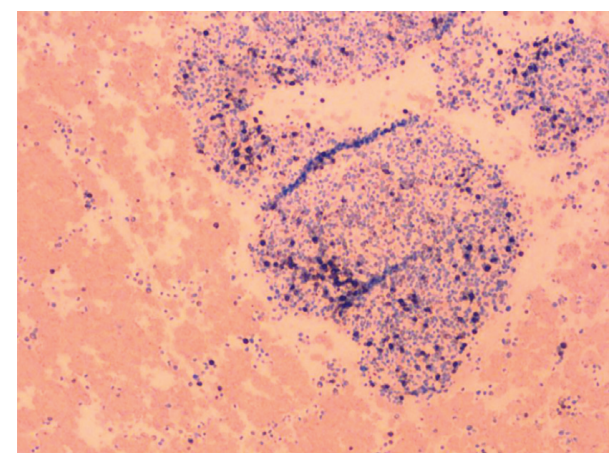

FIGURE 4: Clot stained with CD2 which is positive in mast cells.

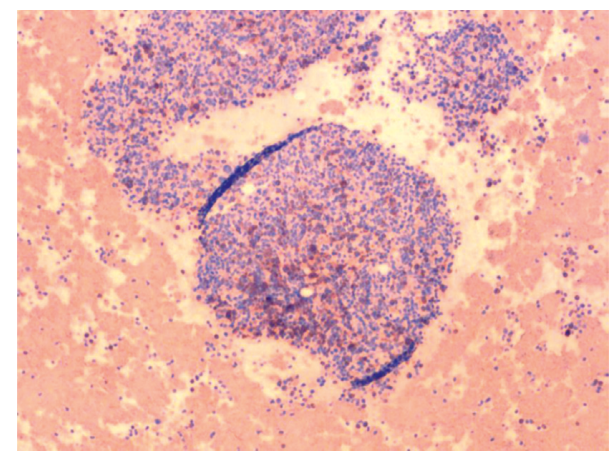

Figure 5: Clot stained with CD25 which is positive in mast cells.
Eosinophils were increased (30\% with an absolute number of $1400 / \mathrm{mcL}$ ) without abnormal features. Monocytes were increased to $12.9 \%$ without absolute monocytosis. Imaging studies (ultrasound and CT scan of abdomen) revealed hepatomegaly (liver $19.7 \mathrm{~cm}$ in length) and splenomegaly (spleen $19.1 \mathrm{~cm}$ in length) with multiple retroperitoneal lymph nodes.

With the patient's prior history of depression and ongoing thrombocytopenia, interferon alfa and 2-chlorodeoxyadenosine were not recommended for treatment of ASM. New avenues of treatments were discussed. Since the mast cells were CD30+, brentuximab vedotin was administered at a dose of $1.8 \mathrm{mg} / \mathrm{kg}$. After therapy, patient developed worsening neutropenia, despite filgrastim and worsening anemia, and thrombocytopenia. The patient also developed Gram-negative bacteremia secondary to a urinary tract infection and became hypotensive and hypoxemic with lactic acidosis. The patient died 2 weeks later in the intensive care unit. Our patient lived for a short time after diagnosis of ASM; hence, there was not enough time for many sequential therapies. He did receive highdose steroids before and concurrently with brentuximab therapy.

2.4. Outcome. The patient deceased within 2 months of initial diagnosis.

\section{Discussion}

Aggressive systemic mastocytosis is an uncommon disorder characterized by neoplastic mast cell accumulation in various organs. The skeletal system, bone marrow, gastrointestinal tract, and spleen are commonly involved. Mast cell infiltration of bone marrow leads to cytopenias, the so-called "C" findings $[5,6]$. Systemic mastocytosis patients have poor prognosis because of multiorgan involvement and dysfunction [7].

Our patient presented with systemic symptoms and severe anemia, workup of which led to diagnosis of underlying systemic mastocytosis and pure red cell aplasia. The diagnosis of ASM was made by a constellation of clinical, cytogenetic, and molecular analyses [8]. Pure red cell aplasia was confirmed by normochromic anemia with very low reticulocyte percentage in presence of normal white cell and platelet counts, along with the finding of cellular marrow that revealed normal myelopoiesis, lymphopoiesis, and megakaryocytopoiesis, but very rare, if any erythroid precursors [9]. The association of mast cell disorder with pure red cell aplasia is rare and has been described only once in the literature [4].

Our patient had first exposure to Agent Orange 45 years earlier and then for the next three years. Agent Orange is a mixture of two chemicals that are phenoxy herbicides: 2,4 dichlorophenoxyacetic acid and 2,4,5 trichlorophenoxyacetic acid $(2,4,5 \mathrm{~T})$. The 2,4,5 $\mathrm{T}$ in Agent Orange was contaminated with small amount of dioxins. The main dioxin involved was 2,3,7,8-tetrachlorobenzo-p-dioxin or TCBD, which is one of the most toxic of dioxins and is classified as a human carcinogen by the U.S. Environmental 
Protection Agency. In the Vietnam War, between 1962 and 1971, the US military sprayed these herbicides. The Centre for Disease Control and Prevention notes that, in particular, there are increased number of cases of acute/chronic leukemias, Hodgkin's and non-Hodgkin's lymphomas, head and neck cancers, prostate cancer, lung/colon cancers, and soft tissue sarcomas occurring in the exposed population. Other reports have included multiple myeloma, AL amyloidosis, and other benign hematologic changes like anemia, leukopenia, and thrombocytopenia. Role of Agent Orange exposure in cytopenia or systemic mastocytosis in our patient remains of concern but cannot be stated with certainty. The complete blood count 2 years before diagnosis of ASM was normal in our patient.

The etiology of anemia in our patient was probably multifactorial: anemia of chronic disease/malignancy, bone marrow mastocytosis, splenomegaly, and pure red cell aplasia. Myelodysplastic syndrome (MDS) and autoimmune hemolytic anemia contributing to the patient's anemia could not completely be excluded. Serum protein electrophoresis was negative for monoclonal gammopathy, and quantitative measurements of IgG, IgA, and IgM were normal. Direct antiglobulin test was not performed initially. Despite frequent red cell transfusions, no crossmatching difficulties were reported by the blood bank. But, 3 weeks prior to the patient's demise, the blood bank reported difficulty in crossmatching for compatible red cells. A direct antiglobulin test performed then detected an IgG-negative complementmediated positive test. The serum erythropoietin level was elevated at $1234 \mathrm{IU} / \mathrm{L}$. High-dose methylprednisone 80$100 \mathrm{mg}$ IV was initiated over the next week. In view of the severe reticulocytopenia and rising liver enzymes, coagulopathy as a result of hepatic involvement of ASM, response to steroids could not be determined. The patient remained transfusion-dependent and developed progressively severe pancytopenia.

Similarly, the etiology of thrombocytopenia was also multifactorial: infiltrating mast cells in the bone marrow and splenic sequestration. Increased megakaryopoiesis as well as dysmegakaryopoiesis in bone marrow raise the possibility of immune thrombocytopenia and MDS, respectively. MDS mutational analysis and FISH was performed to evaluate for critical regions in myelodysplastic syndrome which included deletion of $5 q 31$ and $7 q 31$, enumeration of chromosome 8 , and deletion of long arm of chromosome 20. The studies were negative for all four regions, and JAK 2 study was also negative. Hence, in absence of abnormal cytogenetics, FISH, and flow cytometric studies, the diagnosis of MDS could not be confirmed. Flow cytometry did not demonstrate any increase in the blasts or immature cells. Immunostain for CD34 was positive only in rare cells in the bone marrow. FISH analysis for $t(9: 22)$ BCR/ABL 1 translocation, PDGFRA (4q12), FGFR 1(t 8:11), and PDGRB (5q33) rearrangement was negative. Mutational analysis for MDS detected mutation of ASXL1 and EZH2 genes. These genes are not specific for MDS and have been reported in many myeloid disorders as well as in ASM with unfavourable prognosis $[10,11]$. Mutations in IDH1, IDH2, KRAS, NRAS, and TET 2 were negative.
The favoured diagnosis of bone marrow was ASM. The interpretation was supported by the presence of " $\mathrm{C}$ " findings including cytopenia indicating bone marrow dysfunction, in association with elevated liver enzymes suggesting liver damage and splenomegaly probably associated with hypersplenism. The patient also had diarrhea on presentation. As an infiltrative process, a proliferation of mast cells in the intestinal submucosa causes malabsorption. Release of histamine, both locally and systemically, other peptides, proteases, and generation of excessive quantities of mediators, such as prostaglandin D2, leukotriene C4, and platelet-activating factor are likely to alter gastrointestinal function and motility.

The patient presented with rapidly accumulating, extremely high iron saturation, and raised ferritin level, with negative mutation in HFE gene, which included C282 Y and H63D. Of note, iron saturation and ferritin levels were normal 4 months before diagnosis of ASM. Other causes of iron overload included ineffective erythropoiesis seen in MDS/sideroblastic anemia, thalassemia, and congenital or acquired hemolytic anemia associated with multiple transfusions. These conditions were unlikely in our patient because of the short time course for iron accumulation. A number of acute and chronic liver diseases causing liver inflammation can release stored iron into circulation raising serum ferritin [12]. One such inflammatory condition is hemophagocytosis syndrome (HPS). It is an extremely lethal condition in which excessive activation of immunity leads to tissue destruction. This condition was unlikely in our patient as the ferritin levels are usually over $5000 \mathrm{ng} / \mathrm{ml}$ in hemophagocytosis syndrome, whereas it was below $1000 \mathrm{ng} / \mathrm{ml}$ in our patient. The other feature of HPS patients is the acuity of illness with multiorgan involvement. Though our patient had multiorgan involvement from ASM, the cardinal features of HPS such as fever or rheumatologic symptoms were lacking, making the diagnosis unlikely in our patient. Malignancy can also be associated with elevated ferritin as suggested by a clinical trial published in 2015 [13]. Our patient had both an underlying malignancy and liver injury, the latter most likely contributing to the increased ferritin levels.

Management of any form of mastocytosis involves 3 different strategies: (a) general measures to prevent anaphylaxis, (b) antihistamine (cetirizine, hydroxyzine, and doxepin) and antileukotriene therapy (montelukast and zileuton) to treat symptoms associated with mast cell mediator release, and (c) cytoreductive therapy for advanced disease $[10,14,15]$. Midostaurin is a KIT inhibitor, first-line agent used in advanced disease, regardless of KIT mutation status [16]. Our patient did not receive the drug as it was approved by FDA only recently (April 2017). Tyrosine kinase inhibitors (TKI) such as imatinib have been used in ASM patients who do not have D816V mutation [17]. Our patient did express the D816V mutation and hence did not qualify for TKI therapy. At that time, the available cytoreductive therapies were interferon alfa and 2-CDA (chlorodeoxyadenosine). These drugs tend to have significant side effects with response lasting for short duration. This has led to an increasing need for novel agents with longer response and 
fewer side effects. Another potential therapeutic target CD30 (Ki-1) antigen was identified in patients with advanced ASM, and brentuximab vedotin has been used as an alternative therapy. Our patient received the same $[18,19]$. Though brentuximab vedotin has a better safety profile, our patient was unable to tolerate even a single dose.

Cladribine is indicated in patients with rapidly progressive mastocytosis for rapid debulking and those who failed to respond to midostaurin or TKI. Hydroxyurea is also used in ASM patients, especially those with leukocytosis and/or splenomegaly-associated myeloproliferative neoplasms $[20,21]$. None of the above therapies could be initiated in our patient due to worsening general condition after brentuximab. Hematopoietic stem cell transplant is the only curative option, though it is typically performed in younger adults [22]. PRCA, with or without ASM, is generally managed with regular transfusions for anemia, followed by immunosuppressive or cytotoxic therapy [23].

\section{Data Availability}

The published data used to support the findings of this study (case report) are included within the article.

\section{Conflicts of Interest}

The authors declare that they have no conflicts of interest.

\section{References}

[1] D. D. Metcalfe, "Classification and diagnosis of mastocytosis: current status," Journal of Investigative Dermatology, vol. 96, no. 3, pp. S2-S4, 1991.

[2] D. A. Arber, A. Orazi, R. Hasserjian et al., "Classification of mastocytosis: a consensus proposal," Leukemia Research, vol. 25, no. 7, pp. 603-625, 2001.

[3] J. W. Vardiman, "The 2016 revision to the World Health Organization (WHO) classification of myeloid neoplasms and acute leukemia," Blood, vol. 127, no. 20, pp. 2391-2405, 2016.

[4] L. B. Afrin, "Mast cell activation disorder masquerading as pure red cell aplasia," International Journal of Hematology, vol. 91, no. 5, pp. 907-908, 2010.

[5] P. Valent, C. Akin, W. R. Sperr et al., "Aggressive systemic mastocytosis and related mast cell disorders: current treatment options and proposed response criteria," Leukemia Research, vol. 27, no. 7, pp. 635-641, 2003.

[6] A. W. Hauswirth, I. Simonitsch-Klupp, M. Uffmann et al., "Response to therapy with interferon alpha- $2 b$ and prednisolone in aggressive systemic mastocytosis: report of five cases and review of the literature," Leukemia Research, vol. 28, no. 3, pp. 249-257, 2004.

[7] L. Afrin, "Presentation, diagnosis, and management of mast cell activation syndrome," in Mast Cells: Phenotypic Features, Biological Functions, and Role in Immunity, D. Murray, Ed., Nova Science Publishers, Happauge, NY, USA, 2013.

[8] L. B. Schwartz and A. M. Irani, "Serum tryptase and the laboratory diagnosis of systemic mastocytosis," Hematology/ Oncology Clinics of North America, vol. 14, no. 3, pp. 641-657, 2000.

[9] K. Sawada, N. Fujishima, and M. Hirokawa, "Acquired pure red cell aplasia: updated review of treatment," British Journal of Haematology, vol. 142, no. 4, pp. 505-514, 2008.
[10] M. Jawhar, J. Schwaab, S. Schnittger et al., "Additional mutations in SRSF2, ASXL1 and/or RUNX1 identify a high-risk group of patients with KIT D816V+ advanced systemic mastocytosis," Leukemia, vol. 30, no. 1, p. 136, 2016.

[11] F. Traina, V. Visconte, A. M. Jankowska et al., "Single nucleotide polymorphism array lesions, TET2, DNMT3A, ASXL1 and CBL mutations are present in systemic mastocytosis," PloS One, vol. 7, no. 8, Article ID e43090, 2012.

[12] D. Karam, S. Swiatkowski, P. Purohit, and B. Agrawal, "Highdose steroids as a therapeutic option in the management of spur cell haemolytic anaemia," BMJ Case Reports, vol. 2018, 2018.

[13] A. M. Schram, F. Campigotto, A. Mullally et al., "Marked hyperferritinemia does not predict for HLH in the adult population," Blood, vol. 125, no. 10, pp. 1548-1552, 2015.

[14] J. Turk, J. A. Oates, and L. J. Roberts, "Intervention with epinephrine in hypotension associated with mastocytosis," Journal of Allergy and Clinical Immunology, vol. 71, no. 2, pp. 189-192, 1983.

[15] A. S. Worobec, "Treatment of systemic mast cell disorders," Hematology/Oncology Clinics of North America, vol. 14, no. 3, pp. 659-687, 2000.

[16] J. Gotlib, H. C. Kluin-Nelemans, T. I. George et al., "Efficacy and safety of midostaurin in advanced systemic mastocytosis," New England Journal of Medicine, vol. 374, no. 26, pp. 2530-2541, 2016.

[17] A. Vega-Ruiz, J. E. Cortes, M. Sever et al., "Phase II study of imatinib mesylate as therapy for patients with systemic mastocytosis," Leukemia Research, vol. 33, no. 11, pp. 14811484, 2009.

[18] A. Mehta, V. V. Reddy, and U. Borate, "Anti CD-30 antibodydrug conjugate brentuximab vedotin (ADCETRIS ${ }^{\circledR}$ ) may be a promising treatment option for systemic mastocytosis (SM)," Blood, vol. 120, p. 2857, 2012.

[19] U. Borate, A. Mehta, V. Reddy, M. Tsai, N. Josephson, and I. Schnadig, "Treatment of CD30-positive systemic mastocytosis with brentuximab vedotin," Leukemia Research, vol. 44, pp. 25-31, 2016.

[20] K. H. Lim, A. Pardanani, J. H. Butterfield, C. Y. Li, and A. Tefferi, "Cytoreductive therapy in 108 adults with systemic mastocytosis: outcome analysis and response prediction during treatment with interferon-alpha, hydroxyurea, imatinib mesylate or 2-chlorodeoxyadenosine," American Journal of Hematology, vol. 84, no. 12, pp. 790-794, 2009.

[21] A. Tefferi, "Treatment of systemic mast cell disease: beyond interferon," Leukemia Research, vol. 28, no. 3, pp. 223-224, 2004.

[22] C. Ustun, A. Reiter, B. L. Scott et al., "Hematopoietic stem-cell transplantation for advanced systemic mastocytosis," Journal of Clinical Oncology, vol. 32, no. 29, pp. 3264-3274, 2014.

[23] K. Sawada, M. Hirokawa, and N. Fujishima, "Diagnosis and management of acquired pure red cell aplasia," Hematology/ Oncology Clinics of North America, vol. 23, no. 2, pp. 249-259, 2009. 


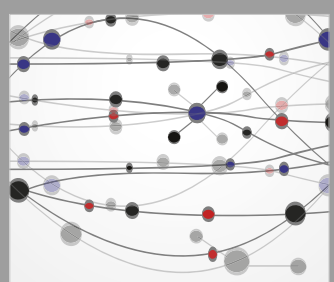

The Scientific World Journal
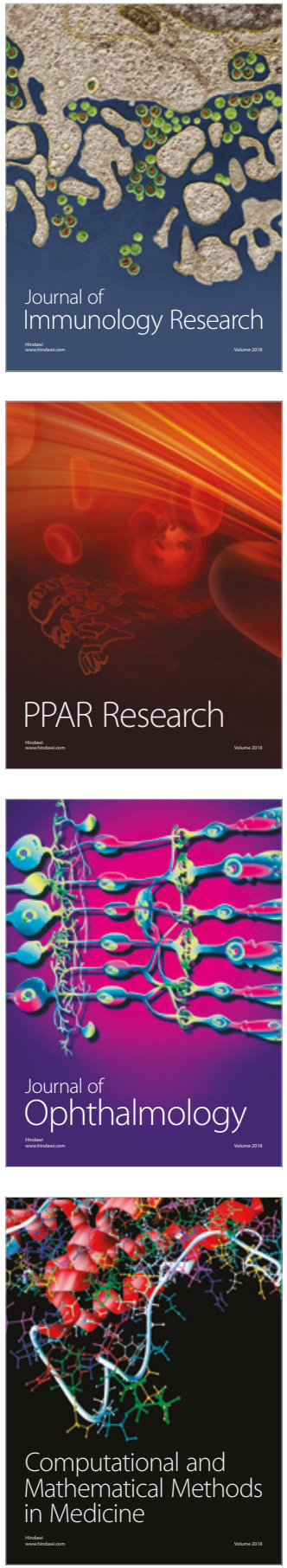

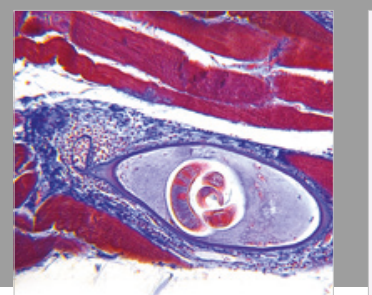

Gastroenterology Research and Practice

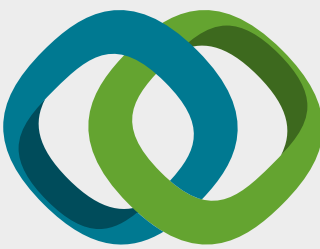

\section{Hindawi}

Submit your manuscripts at

www.hindawi.com
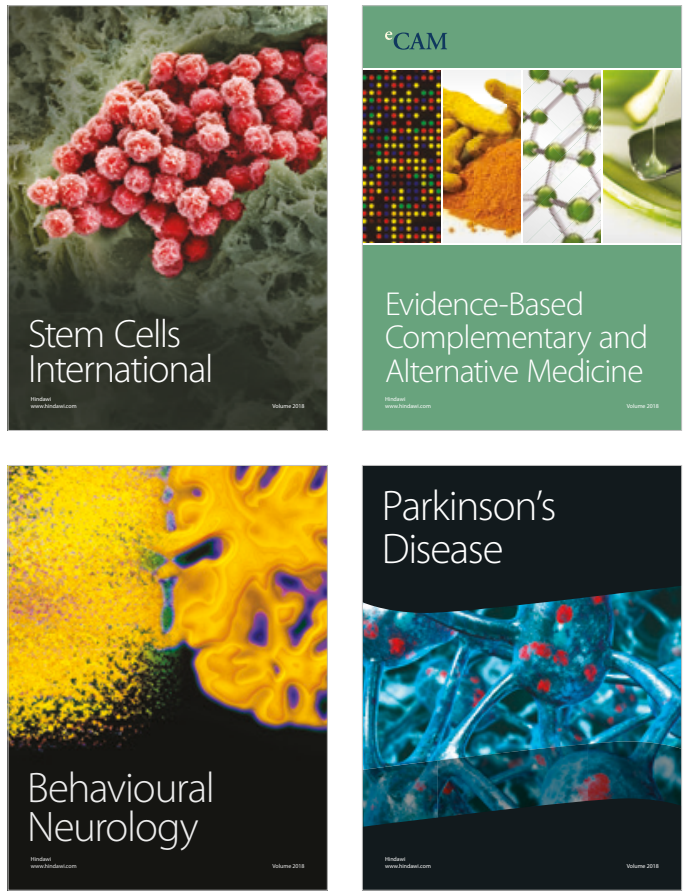

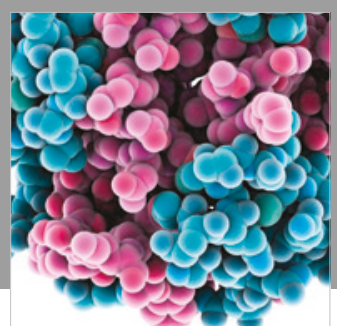

ournal of

Diabetes Research

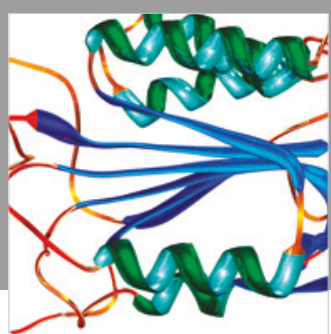

Disease Markers
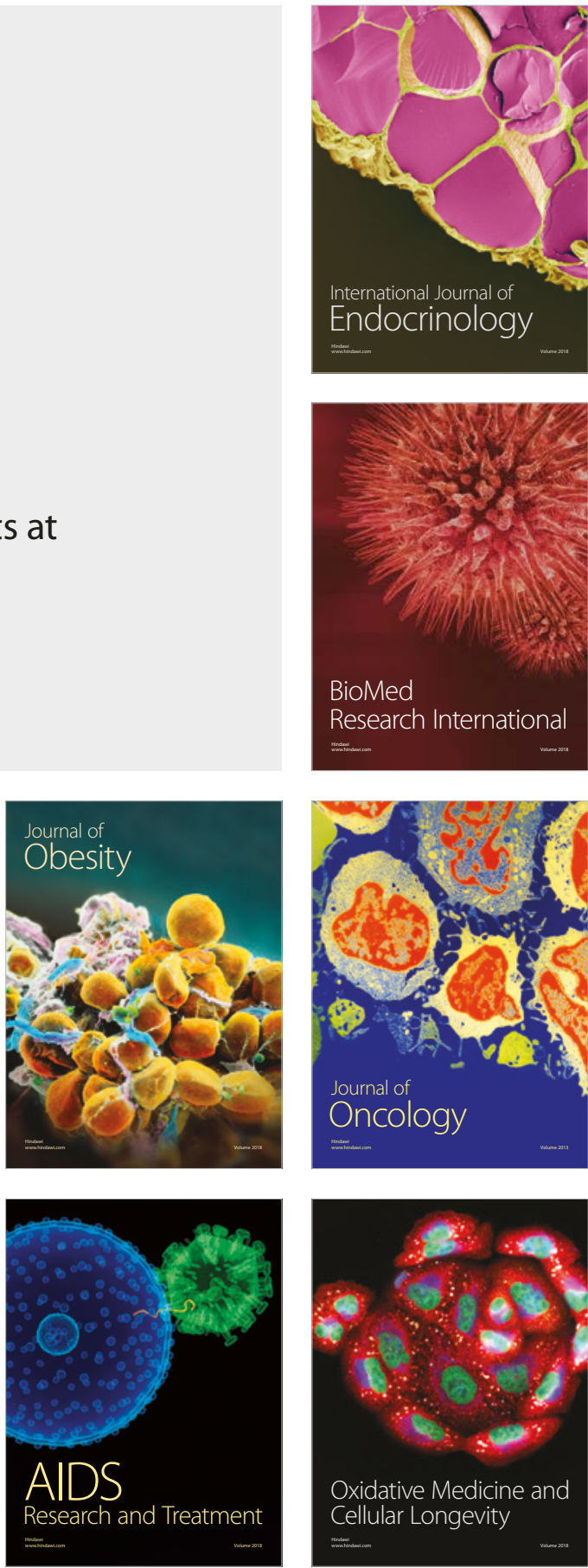